\title{
Molecular Phylogenetic Studies of Caribbean Palms (Arecaceae) and Their Relationships to Biogeography and Conservation
}

\author{
Julissa Roncal ${ }^{1,4} \cdot$ Scott Zona ${ }^{2}$ Carl E. Lewis ${ }^{2,3}$ \\ ${ }^{1}$ Department of Biological Sciences, University of Aarhus, Ny Munkegade 1540, \\ DK-8000 Aarhus C, Denmark \\ ${ }^{2}$ Deparment of Biological Sciences, Florida International University, 11200 SW 8th St., Miami, \\ FL 33199, USA \\ ${ }^{3}$ Center for Tropical Plant Conservation, Fairchild Tropical Botanic Garden, 11935 Old Cutler Road, \\ Coral Gables, FL 33156, USA \\ ${ }^{4}$ Author for Correspondence; e-mail: julissa.roncal@biology.au.dk \\ Published online: 22 August 2008 \\ (C) The New York Botanical Garden 2008
}

The primary address where all authors conducted the research for this article, which was published in Volume 74, Number 1, p. 78, is Center for Tropical Plant Conservation, Fairchild Tropical Botanic Garden, 11935 Old Cutler Road, Coral Gables, FL 33156, USA.

The secondary address for Scott Zona and Carl E. Lewis is Department of Biological Sciences, Florida International University, 11200 SW 8th St., Miami, FL 33199, USA.

The current address of the corresponding author, Julissa Roncal, is Department of Biological Sciences, University of Aarhus, Ny Munkegade 1540, DK-8000, Aarhus C, Denmark. 